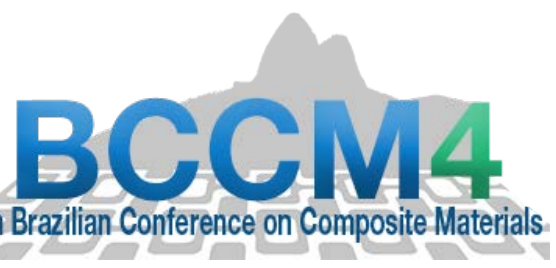

\title{
CURVED PULTRUDED UNIDIRECTIONAL CARBON FIBER COMPOSITE UNDER INTERLAMINAR SHEAR FATIGUE LOADING
}

\author{
Maikson L. P. Tonatto ${ }^{(1)}$, Rafaela G. Rodackievicz ${ }^{(2)}$ and Sandro C. Amico ${ }^{(2)}$ \\ (1) Department of Mechanical Engineering, Federal University of São João Del Rey/MG, \\ Brazil
}

(2) Department of Materials Engineering, Federal University of Rio Grande do Sul/RS, Brazil

https://doi.org/10.21452/bccm4.2018.06.03

\begin{abstract}
Curved pultrusion is a new variation of traditional pultrusion and it has been recently used to produce curved composite components. Due to their excellent mechanical properties, curved composites may be used in aerospace, automotive and naval sectors. However, little is known about their fatigue behavior. In the present work, a short beam shear test (SBS) set up has been used to evaluate fatigue strength of curved pultruded carbon fiber composite samples. A servo-hydraulic machine was used to apply a frequency of $5 \mathrm{~Hz}$, and at 80, 70, 60 and $50 \%$ of the quasi-static strength. The tests were carried out for a stress ratio R of 0.1 , and additional tests were performed for ratio $\mathrm{R}$ of 0.5 . Damage evolution has been observed using the apparent stiffness method. S-N curves have been normalized and the experimental data has been fitted using Basquins' Law. Observed failure and limitations of the SBS test to characterize the interlaminar shear fatigue behavior for curved composites are described and discussed.
\end{abstract}

Keywords: Curved composite, carbon fiber, pultruded, fatigue, short beam test.

\section{INTRODUCTION}

Manufacturing techniques for composite pultrusion materials are commonly used due to factors such as high precision in fiber positioning, high fiber volume fraction, low void content and process automatization. Pultrusion is known to produce flat profiles in varied cross sections [1]. Jansen [2] described that until recently pultrusion was the only high-scale production process for fiber-reinforced profiles and only allowed the manufacture of flat profiles. However, a new method called curved pultrusion has been developed to obtain curved profiles based on new concept of matrix format and matrix motion mechanism. In traditional pultrusion, the matrix is stationery and the fibers are drawn into a resin bath and pulled in order to produced a flat profile. In the curved pultrusion, the die is no longer stationary, but moves back and forth along the profile.

Curved composite structures are currently used in applications where dynamic loading occurs. Most studies treat fatigue life as a two-phase process that includes damage initiation and damage growth. It is not usual to find literature studies dedicated to analyzing fatigue 
behavior in composite structures subjected to loading that predominantly leads to delamination. This can lead to either underestimated or conservative designs. Besides, it is very difficult to find any work on fatigue of curved composite structures.

Bureau and Denault [3] characterized the effect of consolidation on the fatigue strength of continuous glass fiber/polypropylene (CGF/PP) composites. Flexural fatigue tests were performed under three-point bending using traditional flat composite samples and failure was predominantly caused by tensile and compressive stresses in the fiber and the matrix.

Delamination is a very important factor in the design of composite structures subjected to fatigue loading. Its behavior is very particular and depends on the individual components (materials). Some authors have performed specific fatigue studies to understand the behavior of these structures. For instance, Kotik and Ipina [4] studied quasi-static and fatigue $(\mathrm{R}=0.1$; $5 \mathrm{~Hz}$ ) interlaminar shear behavior of flat commercial FML (Glare 1 3/2) employing the shortbeam shear (SBS) test in longitudinal and transverse orientations. Ju et al. [5] described that in laminated curved samples, delamination occurs more easily owing to the high peel stress in the curved region. And the reinforcement effect of grooved Z-pins is investigated for preventing delamination of curved beams.

The present study focuses on the evaluation of curved pultruded carbon fiber composites under interlaminar shear fatigue load. A real scale composite coil was used to obtain the fatigue samples. Experimental tests were carried out at two different stress ratios $(\mathrm{R}=0.1$ and 0.5 ), and at $80,70,60$ and $50 \%$ of the quasi-static strength.

\section{EXPERIMENTAL TESTS}

\subsection{Materials and specimen preparation}

The material used in this study was unidirectional carbon fiber/epoxy. A coil of circular cross section with diameter $12.7 \mathrm{~mm}$ and pitch $36 \mathrm{~mm}$ was manufactured by curved pultrusion. All unidirectional fibers were aligned along to the coil shape. The specimens for testing were cut and polished to the dimensions specified in ASTM D2344 using a manual saw. The specimens were cut to $76.2 \mathrm{~mm}$ long samples as shown in Figure 1 [6].

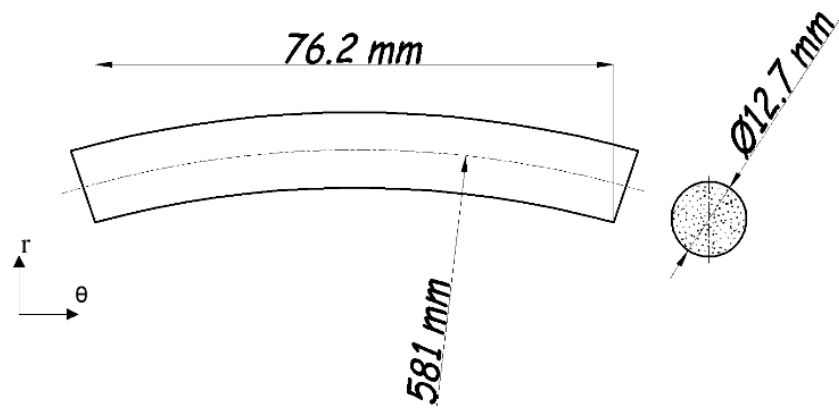

Figure 1: Curved pultruded composite sample and dimensions.

\subsection{Quasi-static short beam test}

A short beam shear test set-up was mounted in an INSTRON 3382 test machine. The test was performed according ASTM D2344. The samples were supported on a flat plate, using as span the length of the samples. Load was controlled with a $100 \mathrm{kN}$ load cell and a loading roller (6 $\mathrm{mm}$ in diameter) was used. The test speed rate was $1 \mathrm{~mm} / \mathrm{min}$ and each test was interrupted at the first major load drop.

The short-beam strength recommended for circular cross-section samples was determined according to $\mathrm{F}^{\mathrm{sbs}}=(2 / 3) \times \mathrm{P}_{\mathrm{b}} / \mathrm{A}$, where $\mathrm{P}_{\mathrm{b}}$ is the maximum load found and $\mathrm{A}$ is the circular 
cross-section of the sample. The test was performed in five specimens and the mean maximum load found was used as the reference value for fatigue loading.

\subsection{Fatigue short beam test}

Fatigue short beam tests were performed under sinusoidal load control. The same device used in the static tests was mounted in a MTS Landmark servo hydraulic machine equipped with a $100 \mathrm{kN}$ load cell. Figure 2 shows a curved sample during the fatigue short beam test. The tests were carried out at a frequency of $5 \mathrm{~Hz}$ and for severities of $80 \%, 70 \%, 60 \%$ and $50 \%$ relative to the static short beam strength $\left(\mathrm{F}^{\mathrm{sbs}}\right)$. The tests were run until a catastrophic failure was identified, until the maximum displacement had reached $20 \%$ in relation to that observed at the first load cycle, or for a maximum of $10^{6}$ cycles. Two different ratios of minimum to maximum stress per load cycles, $\mathrm{R}=0.1$ and $\mathrm{R}=0.5$, were adopted.

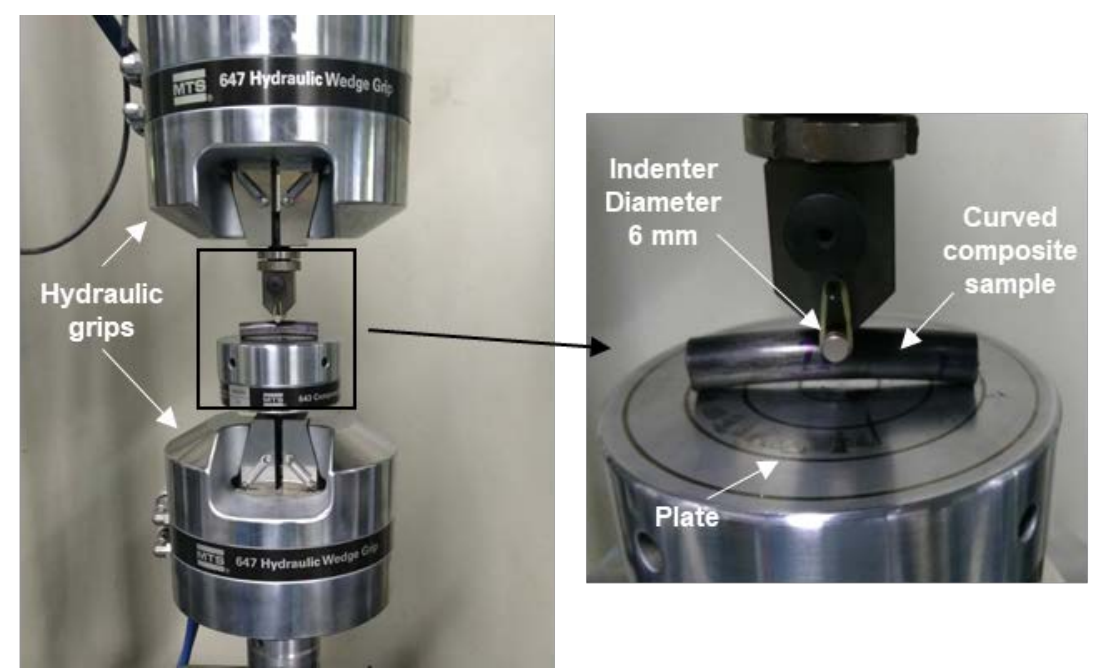

Figure 2: Fatigue short beam test experimental test setup.

\section{RESULTS AND DISCUSSIONS}

Under static load, the specimens were submitted to a increasing load until catastrophic failure occurred close to the mid-plane. The mean maximum load found was $10.9 \mathrm{kN}$, with a coefficient of variation of 5.8\%. The mean short beam strength was $60.2 \mathrm{MPa}$ with a coefficient of variation of $5.5 \%$. The strength values found in these curved pultruded composites was high compared to traditional composite laminates. For instance, Tonatto et al. [7] reported a strength of 22.6 MPa for carbon/PPS curved laminate composite manufactured by filament winding (FW).

Figure 3a shows the normalized stiffness vs. normalized cycle of a sample submitted to $\mathrm{R}=0.1$ and severity $80 \%$. The change in stiffness is a good indicative of sample damage. It is possible to evaluate the normalized stiffness using the "apparent stiffness" parameter, defined as the inverse of displacement. In this case, maximum displacement in each cycle was used to evaluate stiffness change. Three main stages of fatigue are seen in this figure. According to Kotik and Ipina [4], the first stage is a transient in which the rate of maximum displacement decreases. In the second stage, which lasts for most of the life of the sample, a constant rate is observed. In the last stage, the rate of growth of the maximum displacement considerably increases and material failure occurs.

May and Hallett [8] mentions that the change in maximum displacement may be caused by several factors: roller settling-in on the specimen or due to wear, machine compliance, 
internal damage and consequent reduction in stiffness. To eliminate machine compliance and settling-in of the roller, the apparent stiffness, $E_{\text {app }}$, was calculated using the variation of displacement in each cycle, as shown in Eq. 1:

$$
E_{\text {app }} \approx \frac{1}{d_{\max }-d_{\min }}
$$

Figure 3b shows the normalized apparent stiffness $v$ s cycles for $\mathrm{R}=0.1$ and severity $80 \%$. A initial increase in apparent stiffness is seen, which is attributed to fiber straightening and redistribution of load in the early stages of fatigue loading [8]. Nevertheless, considering that predominant failure under interlaminar shear loading is in the resin, not in the fiber, local compressive load caused from the indenter combined with interlaminar shear stress has contributed to this phenomenon. Because of that, some authors do not use this data to precisely quantify the change in stiffness. Even so, delamination easily occurs in curved composite samples submitted to beam loads, causing catastrophic rupture, as easily evidenced in these tests (Figure 3a).

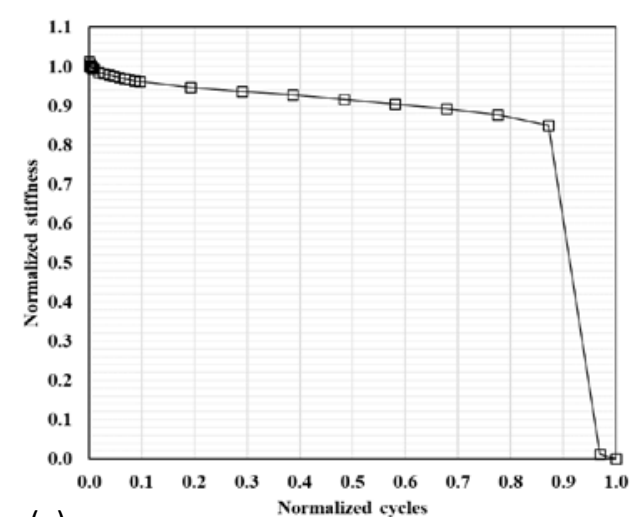

(a)

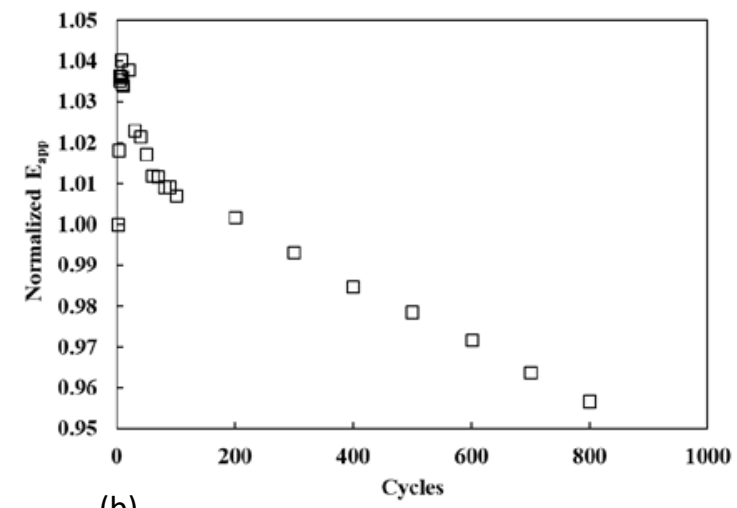

(b)

Figure 3: Normalized stiffness vs. normalized cycles (a) and normalized apparent stiffness vs. cycles (b) for $\mathrm{R}=0.1$ and severity $80 \%$.

All results of the interlaminar short beam fatigue tests are presented in Table 1 and in a severity-log graph (Figure 4). The cycles at failure were obtained as presented before. Three samples were tested at each load condition and the resulting scatter in cycles at failure is can be found in the table. This magnitude in scatter is typical of composite fatigue tests.

Basquins' law was used to fit the fatigue results. This law uses the least squares fit as described in Eq. 2:

$$
\tau=\tau_{\max } \cdot N^{\frac{-1}{b}}
$$

where: $\tau$ is the maximum stress at each load cycle, $\tau_{\max }$ is the quasi-static interlaminar shear strength, $\mathrm{N}$ is the number of cycles and $\mathrm{b}$ is a constant obtained from experiments [8].

Table 1: Number of cycles at failure for each studied condition.

\begin{tabular}{ccc|ccc}
\hline R-ratio & Severity (\%) & Cycles & R-ratio & Severity (\%) & Cycles \\
\hline \multirow{2}{*}{0.1} & \multirow{2}{*}{80} & 900 & & & 4196 \\
& & 300 & 0.5 & 80 & 6000 \\
& 200 & & & 1412 \\
\hline
\end{tabular}




\begin{tabular}{cc|cc}
\hline 70 & 1764 & & 70000 \\
& 1400 & 70 & 1000000 \\
& 9000 & & 1000000 \\
& 62717 & & 548150 \\
& 94062 & 60 & 1000000 \\
& 54924 & & 500000 \\
& 550000 & & 1000000 \\
& 600000 & 50 & 1000000 \\
& 712805 & & 1000000 \\
\hline
\end{tabular}

Figure 4 shows the experimental results and Basquins' law for all severities tested (50, 60, 70 and $80 \%$ ). The curve for $\mathrm{R}=0.5$ is much flatter than for $\mathrm{R}=0.1$ due to the greater load amplitude of the latter in each load cycle. The tests in which the samples reached $10^{6}$ cycles were stopped and this was very common for the samples with $\mathrm{R}=0.5$. In future work, residual strength of these samples will be evaluated.

Kotik and Ipiña [4] mentioned that curved samples submitted to beam loads are more susceptible to delamination. Similar behavior of fatigue curves of curved samples can be observed comparing with flat unidirectional carbon fiber/epoxy prepreg from Hexcel (IM7/8552) available in the literature [8]. Flat samples curves show higher fatigue strength when compared to curved samples due the increase of interlaminar shear stress in curved samples.

Composite laminates generally have well-defined resin rich regions in-between the layers which facilitates delamination, as described by Tonatto et al.[7] . Nevertheless, the decrease in fatigue strength of the curved samples was not as high as it could be because of the typically scattered areas rich in resin of the samples manufactured by curved pultrusion. This characteristic hinders the propagation of delamination.

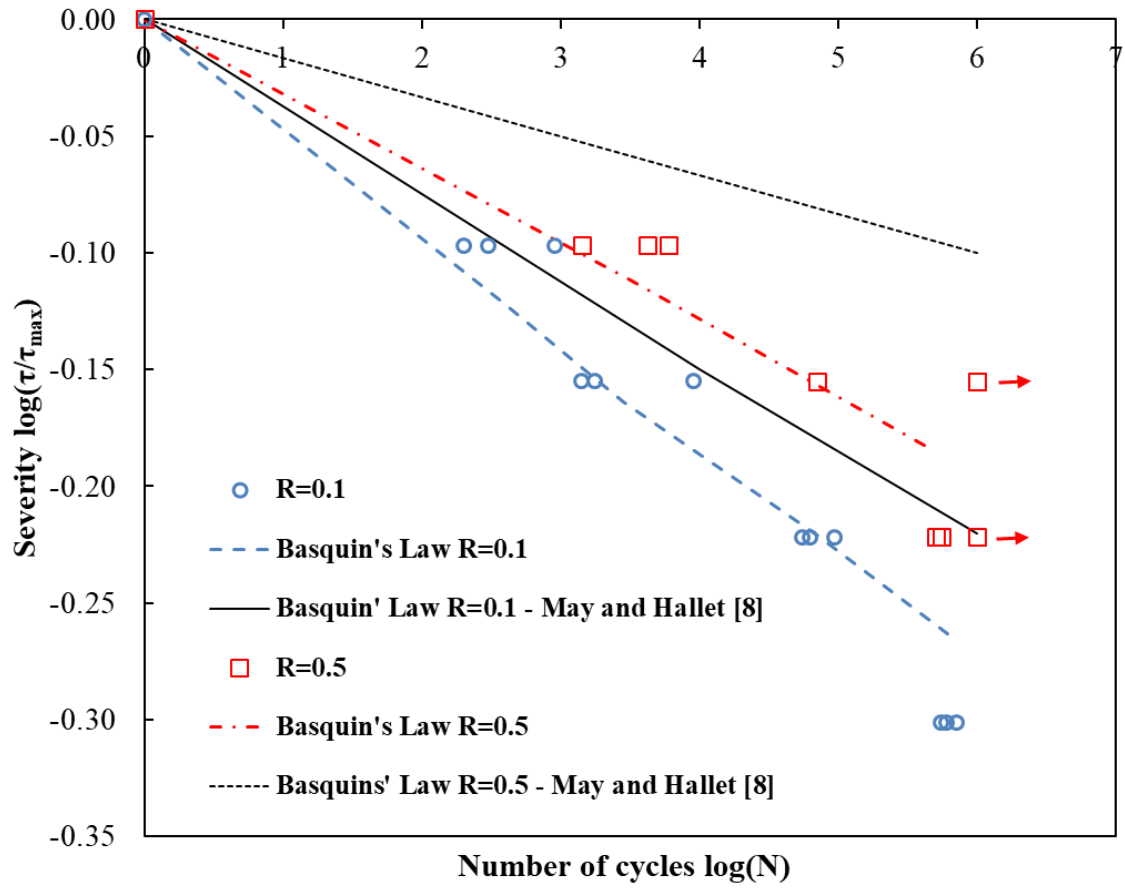

Figure 4: S-N curve (severity log vs. number of cycles log) for curved and flat composite submitted to interlaminar short beam test. 


\section{CONCLUSIONS}

The short beam shear test set-up has been used to evaluate fatigue strength of curved composite samples. Different ratios of load cycle $(\mathrm{R}=0.1$ and 0.5$)$ and different severities (50, 60,70 and $80 \%$ of the quasi-static short beam strength) were studied and apparent stiffness was used to evaluate failure. The curved samples showed catastrophic failure, damage onset was easily detected and delamination was evidenced in the samples after cycling. Also, curved samples have been demonstrated slightly lower fatigue strength compared to flat composite laminates.

Some limitations were found in this study. It is difficult to identify damage initiation with precision. Although curved samples exhibited catastrophic failure, damage can occur immediately before global failure. However, this can only be identified through imaging techniques. Another limitation is the identification of failure for higher stress ratio, e.g. $\mathrm{R}=0.5$, and lower severities, e.g. $50 \%$, because these samples reached $10^{6}$ cycles and therefore may be submitted to more cycles or may be characterized to obtain residual strength.

\section{ACKNOWLEDGEMENTS}

The authors gratefully acknowledge Petrobras for the financial support of this work. Also, CNPq for research support.

\section{REFERENCES}

[1] Neto, F.L. and Pardini, L.C. 'Compósitos estruturais: Ciência e tecnologia', 1st Edn (São Paulo, Edgard Blucher, 2006).

[2] Jansen, K., 'Mass production of curved profiles for car bodies - Process and machines', in 'Automotive Composite Conference and Exhibition', Proceedings of an International Conference, Novi, September, 2016 (SPE Automotive and Composites Divisions, Novi, 2001) $1-13$.

[3] Bureau, M.N. and Denault, J., 'Fatigue resistance of continuous glass fiber/polypropylene composites: consolidation dependence. Compos', Sci. Technol. 64 (2004) 1785-1794.

[4] Kotik, H.G. and Ipiña J.E.P., 'Short-beam shear fatigue behavior of fiber metal laminate (Glare)', Int J Fatigue. 110 (2017) 429-441.

[5] Ju H., Nguyen K., Chae S. and Kweon J., 'Delamination strength of composite curved beams reinforced by grooved stainless-steel Z-pins' Compos. Struct. 180 (2017) 497-506.

[6] Standard Test Method for Short-Beam Strength of Polymer Matrix Composite Materials and Their Laminates. ASTM International. West Conshohocken, p. 8. 2013. (ASTM D2344/D2344M).

[7] Tonatto M.L.P, Forte M.M.C., Tita V. and Amico S.C., 'Progressive damage modeling of spiral and ring composite structures for offloading hoses' Mater Design 108 (2015) 374-382.

[8] May M. and Hallett S.R., 'An assessment of through-thickness shear tests for initiation of fatigue failure' Composites: Part A 41 (2010) 1570-1578. 